\title{
Charter Schools and Bilingual Education: A Case Study of Teachers Negotiating Policy-Making Roles
}

\author{
Meg Gebhard
}

$\mathbf{T}$ he purpose of this ethnographic study is to explore the connection between some educational reform initiatives represented by charter school legislation and the professional experiences of bilingual educators. I examine the interactions that took place between teachers and administrators in a newly formed bilingual charter school using a sociocultural perspective of teachers' professional development. This perspective suggests that teachers' beliefs and practices are shaped by the social, cultural, and historical contexts in which they have been educated. Lortie (1975) describes this socialization process aptly using the concept of an "apprenticeship of observation." This concept describes how what teachers consciously and unconsciously come to know and do is derived from their years of experiences in the classroom as students. Later, their understanding of teaching and learning is further shaped by more immediate contexts. These local contexts include, for example, the quality of teachers' professional development opportunities, the kinds of daily interactions teachers have with students, parents, and colleagues, and the nature of the district and state policies that make certain practices more possible than others (see Talbert \& McLaughlin, 1994 for a discussion of the embedded contexts that matter for teaching and learning).

In the discussion that follows, I address the political dimensions of teachers' policy making decisions as they attempted to negotiate the ways in which these multiple, embedded contexts interact, specifically in regard to the ways in which they attempted to explore the possibilities and limitations of charter school legislation. A study of this nature is warranted for two reasons. First, the literature regarding charter schools has described these schools as offering parents, teachers, and administrators a powerful mechanism for challenging the bureaucratic

Address correspondence to Meg Gebhard, School of Education, Furculo Hall, University of Massachusetts, Amherst, MA 01003. E-mail: gebhard@educ.umass.edu gridlock that plays a role in thwarting meaningful school change (Lasley, 1999; Manno, Finn, Bierlein, \& Vanourek, 1998). Second, the literature regarding charter schools describes these schools as providing teachers and administrators with the professional autonomy they need to respond appropriately and effectively to the local contexts in which they work (Bierlein \& Mulholland, 1993; Dianda \& Corwin, 1994). Given the historic inability of schools to provide linguistically and culturally diverse students with access to an equitable education-particularly one that recognizes the linguistic and cultural resources bilingual students bring to their academic developmentit is not surprising that advocates of bilingual education and a social justice agenda are attracted to the promises of charter school reform. The purpose of this article, therefore, is to explore the power of charter school legislation to support the work of bilingual educators.

To situate this study, I begin by providing a brief review of charter school legislation and the ways in which charter schools can potentially address critical issues regarding the work of bilingual teachers. Second, I describe the methods by which I examined the teaching experiences of eight bilingual teachers in the context of a newly formed charter school in Northern California. Third, I describe how teachers negotiated key policy-making roles regarding issues of authority and control in this context.

In this study, I present Bilingual Charter School Teachers as teachers who have strong ties to the local Mexican American community, are political activists within school contexts, and have the interest and the capacity to debate ideological differences which are inherently part of the process of school change. These debates, in turn, produced a number of compromises that altered the school's approach to pedagogy and student discipline, and in some cases ironically threatened the school's original social justice mission. 


\section{CHARTER SCHOOL LEGISLATION AND THE WORK OF BILINGUAL TEACHERS}

The charter school concept was introduced in 1988 when Ray Budde coined the phrase in his book Education by Charter: Restructuring School Districts. Budde, an educational consultant from Massachusetts, conceived of a "charter for education," analogous to the seventeenth century "charter for exploration." The East India Company, for example, granted a charter to Henry Hudson that specified his mission, a time frame, and the resources that would be made available to him. Hudson, however, was left to his own devices about how he would achieve these goals (Zimmerman, 1992). Applied to education, the concept of a charter allows teachers, principals, parents, and other community leaders to develop a proposal for the operation of a school and to specify the outcomes they hope to achieve. This reform strategy is attractive to conservatives because it provides a low cost way of providing stakeholders with accountability, regulatory freedom, and school choice (Bierlein \& Mulholland, 1993; Dianda \& Corwin, 1994; Lasley, 1999; Manno, Finn, Bierlein, \& Vanourek, 1998). Multicultural educators, on the other hand, are attracted to the opportunity to challenge systemic inequities in education by making schools more culturally representative and accountable to local communities, particularly communities that have historically been marginalized by mainstream schooling practices (e.g., Rofes, 1998; Yancey, 2000).

One of the ways in which charter schools potentially can achieve these goals is by requesting regulatory waivers from state departments of education and by working outside of teacher union agreements in hiring teachers who have the experience and dispositions required to work effectively with bilingual learners and their families but may have taken alternative routes into the profession. This aspect of charter school legislation is crucial given the critical shortage of bilingual teachers and the need to look for new ways to recruit individuals into the teaching profession who have proficiency in a language other than English, a critical awareness of and respect for cultural norms other than those associated with white middle class values, and pedagogical content knowledge that supports bilingual learners in reaching grade level academic expectations (e.g., Ada, 1986; Barreto, 1997; Faltis, 1996; Maxwell-Jolly \& Gandara, 2002; Reyes \& Scribner, 1995). The literature regarding teachers who have expertise in these areas indicates that many of them leave the profession or struggle to remain actively engaged because they work in politically hostile mainstream contexts with few opportunities to participate in professional communities of practice that support their work with students and families (Ada, 1986; Bascia, 1996; Gebhard, 1998; Gebhard, Austin, Nieto, \& Willett, 2002; Torres-Guzmán \& Goodwin,
1995). In the section that follows I describe the ways in which charter school legislation afforded an urban Mexican American community in California the opportunity to tackle many, but certainly not all, of these challenging issues.

\section{THE LOCAL CONTEXT: BACKGROUND, METHODS, AND ANALYSIS}

The Bilingual Charter School ${ }^{1}$ was located in East Maplewood, an urban area in California (the school has since relocated). At the time of the study, East Maplewood was described in various local media pieces as a "tightly knit," "working class," "low income Latino barrio." This neighborhood was sandwiched into a maze of single-digit, one-way streets created by a poorly planned network of railroad tracks and freeway overpasses. The circuitous route leading from the freeway to the school ran past a mammoth canning factory that dwarfed an adjacent elementary school, past an abandoned playground crouched under another expressway on-ramp, and around a well-maintained gas station. One block north of the freeway, in the middle of this industrial zone, the neighborhood surrounding the school took on a more residential atmosphere with a line of twostory Queen Anne row houses, some in need of paint, others with bars on the windows, and a few with welltended gardens. At the end of the street, the Bilingual Charter School sat on a gravel-covered lot surrounded by broken chain-link fence. The school consisted of eight gray, squat, portable trailers. Five of these were individual classrooms; others included a multipurpose room, a restroom facility, and the principal's office. The school served approximately 120 seventh and eighth graders who lived in the surrounding Mexican American community. Official school documents characterized the students as predominately working class, coming from homes where Spanish was spoken, and in need of English as a Second Language (ESL) instruction. ${ }^{2}$ The principal further characterized the students by saying, "about $90 \%$ of the students were below grade level."

A principal, a counselor, a secretary, and eight teachers staffed the school. Of the eight teachers, three were full-time and the other five had part-time, job-share appointments made possible by the school's flexible personnel policies. Parents augmented the work of the official staff by performing other needed secretarial, maintenance, and custodial duties as specified in the school's charter. Collectively, the staff and parents could be described as understanding the issues facing Mexican American students by having lived in or worked with the Mexican American community for most of their private and professional lives. Five out of the eight staff members identified themselves as "Latino" or "Chicano," and 
the three non-Latino, white teachers had either lived or worked in Latin America for extended periods. All of the teachers were highly proficient in English, but had varying levels of proficiency in Spanish. These varying levels did not follow racial lines as evidenced by the fact that the two White teachers were regarded as the more fully bilingual/biliterate staff members. In this regard, similar to many schools that offer bilingual programs in the United States, the label "bilingual teacher" referred to the fact that teachers worked with Spanish-English speaking students, not that they were themselves fully academically proficient in both Spanish and English (Gebhard, 1995).

The teachers had varying degrees of professional experience. One had more than five years of experience in teaching bilingual middle-school-aged children; a second had more than 10 years of experience in teaching at a local bilingual elementary school; a third had 15 years of experience in teaching in a variety of contexts, but with most of her experience at the high school level; another was in his second year of teaching at the middle school level; and the other four were non-credentialed teachers in their first teaching assignments. In this group of four, one had a background in economics, another in Latin American studies, and the remaining two were Ph.D. candidates interested in language education and social and cultural studies.

In sum, the staff could be described as culturally representative of and knowledgeable about the community they served concerning language and culture. The staff also could be described as new to their assigned content area (e.g., math and science), new to teaching middle school students, and/or new to the teaching profession in general. The relative lack of experience in their roles as middle school dual language content-area teachers proved especially challenging to these teachers, given the overwhelming demands placed on them both to develop new classroom teaching practices while at the same time establishing school-wide organizational policies.

In regard to data collection and analysis, ${ }^{3}$ this study took place over nine months, during which time I attended 10 staff meetings and logged an additional 40 hours of fieldwork while conducting interviews and observations external to staff meetings. The purpose of collecting multiple types of data internal and external to staff meetings was to capture the ways in which the multiple, embedded contexts within which teachers worked in this newly formed charter school shaped their teaching practices. The data sources included my written onsite field notes taken during staff meetings, which later formed the basis for writing more formal, fully developed "thick descriptions" (Geertz, 1973). Second, I taped and transcribed informal and formal interviews that focused on the professional and personal histories of the participants as well as on key events that emerged from staff meetings. Third, I conducted an extensive archival review. The documents I collected included local and national media pieces describing this particular charter school, correspondence between the charter-granting school board and the school, correspondence between the principal and the staff, communication between the school and parents, and classroom artifacts in the form of teaching materials and student products.

The analysis process moved through a series of overlapping phases. Phase one consisted of an extensive review of archival documents, field notes from staff meetings and informal interviews, and transcripts from audio taped interviews. This phase culminated in the writing of an interim report that served several functions. First, it brought the data from interviews, observations, and documents together into one highly descriptive single document that simultaneously accomplished the interim tasks of data reduction and analysis (Glaser \& Strauss, 1967; Miles \& Huberman, 1984; Patton, 1990). During phase two I shared this interim report with participants as a way of providing them with potentially useful insights, establishing an atmosphere of openness, and creating a valuable feedback channel. The third phase of data analysis involved the formation of a specific theoretical question (Bogdan \& Biklen, 1992; Glaser \& Strauss, 1967; Patton, 1990).

In regard to my role as a researcher, three interconnected aspects of my identity played a significant role in shaping this ethnography: my whiteness, my experience as an urban middle school ESL teacher, and my affiliation with a local university. As a consequence, three teachers publicly positioned me as an outsider they distrusted because of the power differential that has historically existed between researchers and practitioners, especially between a predominately white, middle-class research community and a predominately Mexican American, working class school community. Three other teachers positioned me in the role of a colleague who was sympathetic to the demands of their work and interested in the specifics of their classroom practices. The principal positioned me as an university based researcher who could document "where the school is now and where it is going." Interestingly, these various understandings of who I was and what I was doing did not fall cleanly along class or racial lines. These understandings however limited my point of entry and my subsequent access mainly to whole-staff meetings. At these meetings my role was that of a "silent minutes-taker." This role placed me in a largely outsider or etic position-a position that allowed me to see interactions among players in the organization without adopting or being locked into either a teacher or an administrative perspective. This outsider stance also allowed me to understand the reality of the organization from the teachers' perspective and to see what factors influenced the formation of their perspective. 


\section{FINDINGS}

\section{Teaching as Political Activity}

In an interview, a teacher emphatically said, "Teaching isn't just a job. It is not about putting in a set number of hours and getting a paycheck. It's about making a commitment to your community." This statement represents a feeling that was echoed in a number of conversations with teachers regarding their reasons for entering the teaching profession, why they accepted positions at the Bilingual Charter School, and how they defined their teaching practices. Specifically, all of the teachers, without exception, talked about wanting to establish better relationships with the community by involving parents in the academic lives of their children, wanting to make the students' language and culture an integral part of the official curriculum, and wanting to give students access to a rigorous academic curriculum. Evidence to this effect presented itself to some degree in staff meetings, but more so in informal conversations with teachers and among teachers as they discussed the kinds of curriculum choices they were making. For example, one teacher described a project in which students were asked to reflect on the images of Latinos in the media in order to deconstruct these images. Another talked at length about incorporating aspects of Mexican history, drama, art, religion, and mythology into her integrated Language Arts/Social Studies instructional block. The strongest piece of evidence, however, that illustrates the degree to which teachers enacted a curriculum that linked classroom activities to the social and political lives of students, was found in the teachers' reactions to issues surrounding the campaign and passage of California's Proposition 187, the denial of services to "undocumented immigrants."

Specifically, one teacher, Jeannie, explained her part in a school-wide examination of immigration history in the United States. With enthusiasm, she described a unit she was creating centering on the study of the film, "El Norte." This critically acclaimed film depicts the life of an "undocumented" Guatemalan woman named Rosa. In approaching the subject, Jeannie gave the students a menu of assignment options, but specified that their final project had to include a piece of artwork, a piece of writing, and an oral presentation. When Jeannie invited me into her room to see how the unit was progressing, the students were arranged in a circle with their projects in their laps. After some initial joking and reluctance about taking the floor, a boy in the class presented his work. The boy had made a folder out of construction paper. The background was black, and on the front cover was glued a cobalt blue cutout drawing of the Statue of Liberty. "Ms. Liberty" was drawn with a thick forearm, a solid body, and an exaggerated crown. Around her neck hung a sign that read, "No non-Americans." At her feet, chiseled into her stone pedestal, was an epigraph that read "Statue of No Liberty." On the inside page the boy had written a poem. His poem was a hybridization of some of his own experiences blended with those of the main character, Rosa. In this sense, the boy appeared to be using the poem as a vehicle for expressing his awareness of the anti-immigrant sentiments prevalent in California. Specifically, the "I" in the poem was in fact the voice of the main character, Rosa, who was Guatemalan and whose parents were "killed" and "kidnapped." To Rosa's voice, he added his own in the final stanza with "No nonAmericans," indicative of his feelings of unwelcomeness in this country.

\section{The Statue of No Liberty}

I remember the bright green grass of my village in Guatemala but now I live in America and the green grass has been replaced by the cold concrete floors of America.

I remember the clear beautiful blue skies in my village but in America those beautiful skies have been turned into smoggy black clouds.

I remember my father who was killed and my mother who was kidnapped but in America my loving parents have been replaced by greedy uncaring bosses.

I remember the stories of a beautiful giant called the Statue of Liberty, but now they have been replaced by a figure with a sign that says America is now occupied. No nonAmericans.

This example of the kind of curriculum and activities teachers promoted reveals the degree to which the teaching at the Bilingual Charter School could be described as "culturally relevant" vis-à-vis the student population they served (Ladson-Billings, 1992). These teachers demonstrated an understanding of the language and cultural experiences of the students in their classrooms, the capacity to relate to students' experiences as Mexican Americans, and to legitimize these experiences by making them part of the official curriculum. This kind of academic validation of the students' language and culture went beyond the lip service or tokenism that are often the hallmarks of uniformed approaches to multicultural and bilingual education (Banks, 1995). In my classroom visits, I observed substantive use of the students' native language and the incorporation of Chicano history, folktales, artwork, and media into the curriculum. Equally important was the attention paid to the political and economic realities of being recent immigrants to California at a time when anti-immigration, anti-bilingual legislation was intensifying. In this sense, the idea that teaching and learning are inherently political activities was acknowledged and embraced by the teachers. This brand of political activism struck me, overall, as creative and intellectualwords not often associated with urban middle school 
teaching. The intellectual and creative climate of the school was something a teacher named Jackie remarked upon. She said,

I had a real prejudice when I went into teaching, which was that I thought I wasn't going to be intellectually challenged.... I felt the work would be interesting, but I thought my colleagues would be stupid because I disliked so many of my teachers when I was going through school... what I found was exactly the opposite.

\section{Negotiating Ideology: Lesson Plans and the Point System}

As Jackie's remarks make clear, the teachers who worked at the bilingual charter school were politically minded and engaged in the creative work of attempting to develop transformative educational practices for the students for whom they were responsible. However, as the following discussion illustrates, teachers often disagreed with one another and the administration regarding their choices of pedagogical practices and schoolwide policies that best lent themselves to meaningful student learning and social change. Specifically, as the year unfolded the staff intensely debated required teacher lesson plans designed to standardize their teaching practices in the direction of a "whole language approach" and the development of a "point system" designed to standardize "acceptable" student behavior. What follows is a summary of how these debates brought to the fore ideological differences among staff members that resulted in the formation of new policies that, in turn, fundamentally changed aspects of the school's original organizational structure and approach to instruction. The character of these changes indicated a movement away from a strong authoritarian style of administration to a more consensus-building, control-sharing partnership among staff members. Ironically, these changes also signaled a movement away from a student-centered to a more teacher-directed conception of pedagogy.

\section{Conflicts Concerning Lesson Plans}

At the beginning of the school year the administrative leaders made it clear that teachers were required to submit lesson plans reflective of teaching in ways that were representative of the Bilingual Charter School's philosophy. This philosophy was described in terms of "cooperative learning" and "whole language instruction." An example of how wedded the school was to cooperative learning was the principal's decision to furnish the rooms with only round tables, rather than desks, to eliminate the possibility of the students ever being arranged in rows. The administration also purchased a series of teacher resource materials that required teachers to rely almost exclusively on cooperative learning methods of instruction.
The teachers, many of whom were at the beginning stages of their careers, agreed ideologically with this approach to instruction but were overwhelmed by the task of turning complex social learning theories into smooth running classroom practices. This difficulty was especially true for the teachers who reported having discipline problems. The nature of these discipline problems struck me as typical of what I know about the problems faced by beginning teachers in middle school, having taught middle school myself. Namely, some students had an active social agenda or a need for control that subtly challenged or overtly competed with the teachers' need to establish a classroom climate conducive to furthering the school's academic program. The tension between the teachers' agenda and the students' agenda was evident during staff meetings and in interviews when teachers described students using foul language, being off task, and, in some cases, shutting down the class with more disruptive kinds of behavior. In the face of these challenges, several of the teachers felt that using group work methods of instruction only made the task of getting and holding their students' attention more difficult. The teachers reported feeling "tense" and "stressed" and responded to these classroom pressures in several ways. One teacher, for example, implemented practices that ran counter to the principles of cooperative learning and asked administrators to exercise more authority in discipline matters.

In their various challenges to cooperative learning, several teachers started incorporating more skill-based activities into the weekly lesson plans that they were required to submit to the office. The reason some teachers initiated this rather significant change in the Bilingual Charter School's policy was best explained by one teacher who said, "With my level of training, this is the easiest way for me to manage the class." By "manage the class," she meant that textbook and workbook activities calmed the classroom down and focused the students' attention on specific completeable tasks that were procedurally familiar both to her and to her students. In addition, she felt that learning "skills" was important. She explained that she once was more in favor of "process" instruction, but now she had started to re-think her position. She said, "I really started to feel I was jumping ahead spending so much time in the day processing things... when what these kids really need to know is what's a noun, what's a verb, put a period at the end of the sentence."

The principal strongly opposed a skills-based approach to instruction and was emphatic that the school's philosophy regarding a process approach was "not negotiable." Defending this position, she invoked the school's charter, saying that the main reason for establishing the school was to get away from textbooks and workbooks that taught isolated skills. Reacting to the principal's stance, the teachers perceived the administration's 
insistence on lesson plans, specifically cooperative learning lesson plans, as administrative control aimed at standardizing their teaching practices and as a threat to their ability to teach in ways they felt were most effective.

Six weeks into the first quarter, Jackie, the teacher who made the comment regarding process-product instruction, decided that she had made a mistake in accepting a position at the Bilingual Charter School and resigned on amicable terms. The reason she gave for her resignation was the realization that working with children was "more taxing" and less "psychologically rewarding" than she had expected. In addition, she said that she held the principal in high regard and respected the Bilingual Charter School's philosophy regarding a more "whole language approach," but she felt the school's philosophy and her own were incompatible.

In response to this resignation, the principal took the opportunity to "reflect" on her relationship with teachers. In discussing the event, she acknowledged:

I don't give teachers the same kind of support I give kids because I figure they're adults and don't need it. But there are tensions between the administration and teachers .... and I need to rethink that, I need to [think] more about teachers [and their professional development needs].

At a staff meeting the following day she shared these feeling by saying, "I am intense, but I don't want that intensity to burn people." Moreover, "I need to be open to challenges... because the bottom line is I succeed if you succeed."

Jackie's resignation and the principal's reaction to this event appeared to be a turning point for the other teachers as well. Up to that point, the teachers had been quietly resentful of, and passively resistant to, the lesson plan policy, but at the following meeting they responded to the principal's willingness to be engaged and, in a sense, seemed to model Jackie's candor in presenting their own disagreements with the principal's position. They framed their disagreements not as personal conflicts between teachers and administrators, but rather as opportunities to discuss teacher professionalism, autonomy, and their individual philosophies regarding teaching and learning. For example, one teacher placed copies of Delpit's (1988) article, "The Silenced Dialogue: Power and Pedagogy in Educating Other People's Children," in staff mailboxes as a way of providing a perspective on the topic of skills-based versus process-based instruction. She also requested 15 minutes of staff meeting time to discuss the article. This was her way of suggesting that skills should have an explicit place within a well-rounded curriculum. The position expressed by the article received mixed reviews from the other teachers and administrators, but the practice of bringing research into the discussion gained currency.
At the following staff meeting another teacher exercised his right to place items on the staff meeting agenda and, in doing so, placed the whole notion of required lesson plans in question. In opening this discussion, he said lesson plan writing was a functional activity when he was doing his student teaching and in his first teaching assignment. Now, however, it felt like a time-consuming task that served little purpose. He felt it was "artificial, stressful, and in the way of creativity." He added that it made him feel as if he were not being "trusted as a professional."

At the same meeting another teacher explained, with agreeing nods from two others, that as a new teacher she did not mind writing lesson plans because they were helpful to her and her teaching partner. She also agreed with the principal's position that it was important to "make teachers accountable" and "to hold teachers to higher standards," but she objected to the notion that there was a "right" and "wrong" kind of lesson plan. Echoing Jackie's objection to a strictly prescribed "whole language" approach, she felt the feedback she had received on her lesson plans did not give her room to teach in ways she felt were most beneficial to her students. She gave the following example: She wanted to test her students on their math facts, but was aware that giving a test based on a drill and practice method "wasn't okay." She went on to describe how the dynamic between her and administrators had created a situation where she was writing two lesson plans, one that reflected what the "office wanted" based on cooperative, process learning and a different one for herself that incorporated more attention to skills. A third teacher summarized the different perspectives by saying there was a "need for accountability" but there was also a need for "teachers to have a voice or they start to feel fried." She added, "It is conceptually flawed if teachers are not involved in policy." Her suggestion was to establish a "professional community" wherein teachers could present and reflect on their work.

Over the course of the next few weeks, a compromise was reached that reflected elements of both perspectives. Teachers were required to submit lesson plans twice a month, with every other staff development meeting given over to content area teams. These content area team meetings, or "cores," were intended to provide teachers with a forum for presenting lesson plans and as a way of creating a professional community of practice (CochranSmith \& Lytle, 1999; Louis \& Kruse, 1995). Although this professional community proved fragile, and ultimately a casualty of the number of demands placed on the staff's time, the administration's willingness to meet the teachers halfway, as well as to tolerate different approaches to teaching, did much to ease tensions and to reduce the kinds of defensive teaching routines that were previously in evidence. By the second quarter, talk surrounding the lesson plans policy, which dominated the agenda in the first quarter, was no longer prevalent, indicating 
that a kind of "domain consensus" had been established. The principal realized that the teachers' ideologies were going to determine classroom instructional practices in ways that were resistant to her administrative controls.

\section{The Point System}

Around the same time that challenges to the school's lesson plan policy were being negotiated between teachers and principal, the school counselor recognized the need for action regarding the school's discipline policy. Previously, several teachers had turned to the principal to address matters of student behavior that they felt were beyond their control and that kept them from their primary responsibility of teaching. The administrators believed that these were challenges the teachers needed to work out in their own classrooms by developing strategies for working with specific students who reacted to school in unproductive ways. Unfortunately, several teachers did not have the experience to help them develop strategies, nor did they find it helpful to try a strategy that worked for more experienced teachers. The administration's stance toward discipline instilled in teachers a perception that they were not being "supported" and that administrators were "taking the kids' side." The counselor's strategy was to ask teachers individually to suggest the elements they specifically wanted in a new policy and to draft a new policy based on these suggestions, that became known as "the point system." Over the next four months, the "point system" dominated staff meeting discussions as it went through a number of phases and was further shaped by parents, teachers, administrators, and the Bilingual Charter School's Board of Directors. By mid-April one teacher was cochairing a committee focusing on the issue.

The system, based on a parent's rendering of the procedure into a single format, became a streamlined, codified policy. A summary of this policy is as follows: Each student had a "disciplinary point report" on file. If a student broke a rule, a teacher or an administrator could give him or her a specified number of points based on the nature of the infraction. For example, if a student were "tardy" he or she would incur one point. If he or she were involved in some kind of "disruptive behavior" such as "fighting" he or she would receive 10 points. Over the course of the year, if a student acquired 20 points, he or she would be expelled.

These points were intended to trigger specific checks within the system before expulsion became necessary. These checks included parent conferences, student contracts, and other types of interventions at set point levels. In addition, a student who was to be expelled would have the right to appeal the decision in front of the School Board and possibly re-enter the school with a credit line of an additional five points. If a student used all of these points, there would be no option for a second appeal and the student would be permanently expelled.

In reflecting on this policy, a number of perspectives emerged that crossed administrative-teacher lines. For example, two members of the "old" staff (meaning staff members who were rehired from the previous year and who generally agreed with the principal) felt that the point system "helped" because it sent students a message about "being responsible." They agreed that if a student committed an infraction repeatedly, despite attempts to help the student, the school did not have options other than expulsion, given the lack of support services and a need to set high standards. Many of the "new" teachers (meaning new hires) agreed and added that the point system "created a bottom line" regarding expectations and "norms of acceptable behavior." The principal, however, was critical of the policy because she saw it as running counter to the underlying rationale for the school. From her perspective the school's mission was to meet the needs of the students in the community and these were the very students who were likely to have trouble in school. Expelling students, she said, "is going to be very hard for me, especially in certain cases." The case she highlighted involved a girl who had accumulated absences when caring for her younger brothers and sisters at home. Since the policy had been implemented she had acquired four such absences, totaling 20 points. The principal remarked, "I'm concerned about how this [case] fits with our charter."

The staff recognized this case as an unanticipated, damaging consequence of the point system. In the following discussion, issues of professional autonomy and issues regarding standardization as a control mechanism surfaced, just as they had during the earlier discussion of the lesson plan policy. For example, one teacher who was usually not aligned with the principal agreed with her critique. Jokingly, he quipped that the point system reminded him of the "three strikes and you're out" rule and the "California Penal Code." On a more serious note, he added, "So much is teacher judgment. I look the other way with some kids who are making an effort because part of it is me as a teacher knowing where the kid is at...I feel like the point system takes it out of my hands." He closed with, "I hardly ever give points anymore." Another teacher added that discipline was really a question of "individual style.... You have to do it your way and I'll do it my way." A third teacher, who played an active role in shaping the policy and supported it on the whole, agreed with the principal that expelling students might "label" them in ways that would "identify them as a bad kid in the long run." She talked about how giving points "was working" in some cases with some students, but she did not want to see it "backfire."

As the discussion evolved, the teachers looked for ways to modify the policy to lessen the likelihood of students being unfairly expelled, but without 
compromising the goals of the new policy. One suggestion was to roll back the points to zero at the beginning of the following term. The majority of the teachers felt such a move would send a mixed message that would be damaging in the long run. The principal added that, once the policy was codified and had set parameters under which students had already been expelled it was a legal matter, and changing it would be difficult. In concluding the discussion, staff members, with one exception, voted to keep the point system in its proposed form. The one exception was the principal. In taking this vote, however, several teachers publicly acknowledged that in the future assigning points was going to be much more of a subjective matter because they did not want to be the one who assigned the determining point. They also felt that they needed to intensify their role in the hearing process. Ironically, the teachers closed the meeting by talking about protecting students from the very policy they had created.

\section{SUMMARY AND IMPLICATIONS}

The purpose of this investigation was to examine how the role of a "bilingual teacher" as an organizational participant changed over the course of a year in the context of a newly formed bilingual charter school. The findings from this study suggest that these bilingual teachers found ways to challenge key school policies and to assert greater control and responsibility over classroom life. In analyzing my findings, key aspects of the school's structure and culture were significant. These teachers had been selected in accordance with the school's commitment to a social justice agenda and to equity in education for bilingual students and they shared a core set of values and practices (e.g., substantive use of the students' native language in classroom practices and the incorporation of Chicano history and the politics of immigration into the curriculum).

However, as I have noted in the discussion above, ideological differences within this core set of values surfaced as the year unfolded. Guided by the school's socialization process, teachers debated differences in beliefs regarding best practices and issues of control. These debates produced a number of compromises that altered the school's character and in some cases began to threaten the school's original social justice mission, particularly concerning issues of teacher authority and control.

A discussion of these findings, juxtaposed to the topic of educational reform and the work of bilingual teachers raised at the beginning of this article, highlights a number of tensions regarding charter school legislation, school change, and bilingual education. First, charter school advocates maintain that substantive school change can be realized if like-minded teachers and administrators break free from broader institutional structures that work to reproduce an inequitable social order. In the case of the
Bilingual Charter School, this position seems partially true. Allowed to employ non-credentialed teachers, the Bilingual Charter School was able to attract a staff predisposed to supporting a bilingual, social justice agenda. Second, teachers had a voice in school governance and curriculum development. As a result, teachers were able to create part-time, job-share appointments and to design innovative school-wide thematic units focusing on politically relevant topics. The importance and the difficulty of implementing these kinds of significant changes has been documented by a number of studies that describe the failure of systemic school reforms to meet the needs of California's linguistically and culturally diverse students (Gebhard, 2000; Little \& Dorph, 1998; Olsen, 1994).

Despite the importance of these gains, Bilingual Charter School teachers, especially those new to the profession, were overextended in ways that simultaneously compromised the school's goals and the promise of charter school legislation. Specifically, the findings from this study reveal that nearly all of the Bilingual Charter School teachers were under-prepared and undersupported as they tried to go about the work of teaching a body of academic knowledge in two languages in an organization that was just evolving. In making these remarks, I am not suggesting that fault rested with individual teachers or the principal, but rather with the larger policy context in California during the mid-1990s. Specifically, California's charter school legislation made no start-up funds or start-up time available to teachers and administrators to assist them in creating a new school. Resources in the form of funding and time might have lessened the need for beginning teachers to compensate for so many missing pieces of the school's organization-missing pieces that ultimately distracted teachers from their main classroom responsibilities. Moreover, California's charter school legislation was not part of a broader, coherent, and comprehensive set of policies designed to support the professional development of linguistically and culturally diverse teachers at a time when the state's student population was becoming increasingly diverse (Gebhard, 2000; Olsen, 1994). As a result, the Bilingual Charter School had the overwhelming dual task of delivering innovative instruction to a historically disenfranchised group of students while simultaneously trying to identify, recruit, and support the professional development of a cadre of culturally responsive teachers.

The phenomenon of school change, however, involves more than an adequate supply of funds and other material resources. It also involves confronting naturalized assumptions about the beliefs and practices associated with modern schooling and, ultimately, about power (e.g., Miramontes, Nadeau, \& Commins, 1997; Popkewitz, 1991). These naturalized beliefs and practices are often the most complex and difficult aspects of school change because they are hidden in what Meyer and 
Rowan (1977) call expected "ceremonies" and unchallenged "myths" that subtly work to displace the stated purposes of schooling. McNeil (1986) provides an example of Meyer and Rowan's thesis in her analysis of how the goal of developing an understanding of democracy through the study of American history gets lost when secondary schools focus mainly on rituals aimed at controlling both students and teachers. She writes:

When the school organizations become centered on managing and controlling, teachers and students take school less seriously. They fall into the ritual of teaching and learning that tends toward minimal standards and minimal effort. This sets off a vicious cycle. As students disengage from enthusiastic involvement in the learning process, administrators often see the disengagement as a control problem. They then increase their attention to managing students and teachers rather than supporting their instructional purpose (McNeil, 1986, p. xviii).

The findings from this study indicate that the Bilingual Charter School's policies and practices were moving in a direction that "centered on managing and controlling." Administrators attempted to control the teachers' pedagogical practices by requiring specific kinds of lesson plans, and the teachers attempted to control student behavior by implementing a point system that led to the expulsion of outliers and attempted to normalize the behavior of the rest. These attempts were productive in some instances, but had ironic consequences in others (e.g., Jackie's resignation mid-year and the expulsion of students the school was designed to support).

An important aspect of this process of policy negotiation is that it blind-sided many staff members and left them feeling demoralized. Specifically, the principal and the teachers all commented on how unexpectedly more difficult the work of school reform was. They talked in ways that suggested that they initially believed that their common commitment to improving the education of Mexican American students would eliminate many other differences and make running a school a much less difficult task. This belief appears to be a powerful charter school myth in the Meyer and Rowan (1977) sense. This myth suggests that issues of ideology regarding teaching and learning and, ultimately, authority and control will dissipate when schools hire the right staff and break away from bulky top-down bureaucracies. One need only look at the number of publications reviewed earlier for support of this myth (Bierlein \& Mulholland, 1993; Dianda \& Corwin, 1994; Lasley, Ridenour, TalbertJohnson, \& Raisch, 1999). In light of the experiences of participants in this study, the charter school myth of improvement through bureaucratic freedom and local control is a gross oversimplification of the complexities of teaching, the intricacies of organizations, and the difficulty of achieving substantive change. The findings from this study suggest that this myth functions because school reformers, myself included, tend to assume that the forces of social reproduction are located external to us in identifiable school structures and practices rather than embodied within us a result of having been socialized into accepting "regimes of truth" regarding power and control and what counts as teaching, learning, and schooling (Foucault, 1980, p. 131).

\section{NOTES}

1. All names are pseudonyms.

2. Official documents report that $85 \%$ of the students were "Latino" and spoke Spanish as their first language, 76\% were eligible for a free or reduced lunch, and $65 \%$ were designated as "Limited English Proficient" (LEP).

3. See Gebhard (1999) for a fuller description of the methods of this study.

\section{REFERENCES}

Ada, A. (1986). Creative education for bilingual teachers. Harvard Educational Review, 56(4), 386-394.

Banks, J. (1995). Multicultural education: Historical development, dimensions, and practice. In J. Banks \& C. McGee Banks (Eds.), Handbook of research on multicultural education (pp. 3-24). New York: Macmillan.

Barreto, R. M. (1997). Reform in teacher education through the CLAD/BCLAD policy. Multicultural Education, 5(2), 11-15.

Bascia, N. (1996). Inside and outside: Minority immigrant teachers in Canadian schools. International Journal of Qualitative Studies in Education, 9(2), 151-165.

Bierlein, L., \& Mulholland, L. (1993). Charter school: Expansion of a viable reform initiative. Tempe, AZ: Morrison Institute for Public Policy, Arizona State University, Tempe.

Bogdan, R., \& Biklen, S. K. (1992). Qualitative research for education: An introduction for theory and methods. Boston: Allyn \& Bacon.

Budde, R. (1988). Education by charter: Restructuring school districts: Key to long-term continuing improvement in American education. Andover, MA: The Regional Laboratories for Educational Improvement of the Northeast \& Islands.

Cochran-Smith, M., \& Lytle, S. L. (1999). The teacher research movement: A decade later. Educational Researcher, 28(7), 15-25.

Delpit, L. D. (1988). The silenced dialogue: Power and pedagogy in educating other people's children. Harvard Educational Review, 58(3), 280-298.

Dianda, M. R., \& Corwin, R. G. (1994). Vision and reality: A firstyear look at California's charter schools. Los Alamitos, CA: Southwest Regional Laboratories; U.S. Dept. of Education, Office of Educational Research and Improvement, Educational Resources Information Center.

Faltis, C. (1996). Learning to teach content bilingually in a middle school bilingual classroom. Bilingual Research Journal, 20(1), 29-44. 
Foucault, M. (1980). Power/knowledge: Selected interviews and other writings, 1972-1977. New York: Pantheon.

Gebhard, M. (1995). Peeling back the bilingual label: An ethnographic study. Paper presented at the annual meeting of the American Association for Applied Linguistics, Long Beach, CA.

Gebhard, M. (1998). A case for professional development schools. Tesol Quarterly, 32(3), 501-510.

Gebhard, M. (1999). The professional development of second language educators in a context of reform. Paper presented at the meeting of Teachers of Speakers of Other Languages, New York, NY.

Gebhard, M. (2000). SLA and school restructuring: Reconceiving classroom SLA as an Institutional phenomenon. Unpublished doctoral dissertation, University of California at Berkeley.

Gebhard, M., Austin, T., Nieto, S., \& Willett, J. (2002). “You can't step on someone else's word": Preparing all teachers to teach language minority students. In Z. Beykont (Ed.), The power of culture: Teaching across language differences (pp. 219-243). Cambridge, MA: Harvard Education Publishing Group.

Geertz, C. (1973). The interpretation of culture. New York: Basic.

Glaser, B. G., \& Strauss, A. L. (Eds.). (1967). The discovery of grounded theory: Strategies for qualitative research. Chicago: Aldine.

Ladson-Billings, G. (1992). Liberatory consequences of literacy: A case of culturally relevant instruction for African American students. Journal of Negro Education, 61(3), 378-391.

Lasley, T. (1999). The charter school conundrum: An introduction to the problem. Education and Urban Society, 31(4), 387-388.

Lasley, T. J. II, Ridenour, C., Talbert-Johnson, C., \& Raisch, C. (1999). Charters: A value added opportunity for urban teachers? Education and Urban Society, 31(4), 499511.

Little, J. W., \& Dorph, R. (1998). Lessons about comprehensive school reform. Berkeley, CA: SB 1274 School Restructuring Study, University of California, Berkeley.

Lortie, D. (1975). School teacher. Chicago: University of Chicago Press.

Louis, K. S., \& Kruse, S. D. (1995). Professionalism and community: Perspectives on reforming urban schools. Thousand Oaks, CA: Corwin.

Manno, B. V., Finn, C. E., Bierlein, L., \& Vanourek, G. (1998). Charter schools: Accomplishments and dilemmas. Teachers College Record, 99(3), 537-558.

Maxwell-Jolly, J., \& Gandara, P. (2002). A quest for quality: Providing qualified teachers for California's English learners. In Z. Beykont (Ed.), The power of culture: Teach- ing across language differences (pp. 43-70). Cambridge, MA: Harvard Education Publishing Group.

McNeil, L. M. (1986). Contradictions of control: School structure and school knowledge. New York: Routledge \& Kegan Paul.

Meyer, J., \& Rowan, B. (1977). Institutionalized organizations: Formal structure as myth and ceremony. American Journal of Sociology, 83(2), 340-363.

Miles, M. B., \& Huberman, A. M. (1984). Drawing valid meaning from qualitative data: Toward a shared craft. Educational Researcher, 13(5), 20-30.

Miramontes, O. B., Nadeau, A., \& Commins, N. L. (1997). Restructuring schools for linguistic diversity: A California Tomorrow research and policy report from the Education for a Diverse Society Project. New York: Teachers College Press.

Olsen, L. (1994). The unfinished journey: Restructuring schools in a diverse society. San Francisco, CA: California Tomorrow.

Patton, M. Q. (Ed.). (1990). Qualitative evaluation and research methods. Newbury Park, CA: Sage.

Popkewitz, T. S. (1991). A political sociology of educational reform: Power/knowledge in teaching, teacher education, and research. New York: Teachers College Press.

Reyes, P., \& Scribner, A. P. (1995). Educational reform, students of color, and potential outcomes. High School Journal, 78(4), 215-225.

Rofes, E. (1998). How are school districts responding to charter laws and charter schools?: A study of eight states and the District of Columbia. Berkeley, CA: Policy Analysis for California Education, University of California.

Talbert, J., \& McLaughlin, M. (1994). Teacher professionalism in local school contexts. American Journal of Education, 102(1), 123-153.

Torres-Guzmán, M., \& Goodwin, A. L. (1995). Urban bilingual teachers and mentoring for the future. Education $\mathcal{E}$ Urban Society, 28(1), 48-66.

Yancey, P. (2000). Parents founding charter schools: Dilemmas ofempowerment and decentralization. New York: Peter Lang.

Zimmerman, J. (1992, December). Charter schools: In search of the new world of education. Far West Focus on Changing School Practices, 1-4.

Meg Gebhard is an assistant professor in the School of Education at the University of Massachusetts Amherst. Her research interests include second language literacy development, the work of second language educators, and the implications of current school reform efforts for language learners and their teachers. 